\title{
Demand Dynamics of Light Engineering Sector of Bangladesh and Recommendations for Local Enterprises
}

\author{
Fayez Uddin Ahmad ${ }^{1}$, Sheikh Morshed Jahan ${ }^{2}$ \\ ${ }^{I}$ Student of Doctor of Business Administration, Institute of Business Administration, University of Dhaka \\ ${ }^{2}$ Associate Professor, Institute of Business Administration, University of Dhaka
}

\begin{abstract}
Light engineering is a sector which makes small and medium machineries and spare parts. Spare part business is one of the main lines of business of Bangladesh's light engineering sector. In Bangladesh workers of light engineering sector are highly efficient with their craft. Yet, local market is dominated by imported spare parts. Demand side analysis is needed to find out why such is the case. This paper measures perceptions and attitude of buyers towards local spare parts. In product attributes, it is found that local spare parts are not very far behind in comparison with imported parts. While that is the case, further in the paper causes of dominance of imported parts were discovered and recommendation made for dominance of local makers in the local market.
\end{abstract}

\section{Introduction}

The word "engineering" invokes in one's mind of something which is critical, difficult to understand and only best of brains and minds can be involved with this. It seems that that there is a rescue. Just introduce the word "Light" in front and complicacy plummets. Light engineering is a sector of engineering which is dealt by people whom we can call "engineering artisans". A visit to a one of these very small engineering shops in Bangladesh will surprise the visitors and force to ask questions like "How come these people with almost no education, create or modify such engineering objects?" Light engineering is a sector which deals with small engineering objects like machine parts, auto parts, small machineries, and plastic products or even in some cases full scale small industrial machine. It helps industrial, agricultural and construction sectors by manufacturing a wide range of spare parts, castings, molds and dices, oil and gas pipeline fittings and light machinery, as well as repairing those[5]. The sector spreads all over the country. Contribution of the sector in the GDP is 2\% [5] also cited as $2.15 \%$ [7]. Most of the product of the sector is consumed internally in the country. Sector supplies to the local industries. More often than not the sector caters to the need of local industries. Most businesses of the sector is therefore business to business. A study conducted by International Finance Corporation (IFC) in partnership with UK Department for International Development and Norwegian government shows that light engineering sector has in its employment 6, 00,000 peoples involved in 50,000 micro enterprises and 10,000 Small and Medium Enterprises. Another study conducted by Bangladesh University of Engineering and Technology however, estimates that light engineering sector comprises of around 40,000 enterprises employing around $8,00,000$ peoples [4].

The sector works on the basis of order placed on random basis. It is like local grocery shop, delivery of product occurs when ordered. If there is no customer walking in, there is no business. Business is highly volatile and really depends on the luck. Organized and coordinated business model are almost nonexistent. Apart from the local consumption, the sector also contributes to the export of the country albeit negligible as compared over 82.01\% in financial year 2015-16 of total export from RMG sector [1].Light engineering is a very important sector of the economy in terms of employment generation and poverty reduction. As is said in the opening paragraph that light engineering sector employs people who come from the disadvantaged part of the economy. They are disadvantaged in terms of formal education received and income group. If these people were not employed by the sector, it would have been difficult to employ these people in any other sector. Some of them, who have gathered experiences by working longer in the sector, even earn a good amount of money. The sector supplies both spare parts and complete machine. Spare parts are supplied in all subsectors (listed later in the paper). However, spare parts market is dominated by imported spare parts. This paper studies perceptions and attitudes of consumers of spare parts in an effort to come up with recommendations which can replace purchase behavior in favor of local spare parts in place of imported ones.

\section{Current State of the Sector}

Light engineering sector is mainly a capital intensive sector [5]. Whichever country wants to grow this sector must be ready to infuse enough capital into the sector. Due to lack of capital in the sector, Bangladesh light engineering sector is reeling. People who work in the sector are really skilled albeit they mostly depend on their human measurements and judgments rather than any computer aided designs. Light engineering sector of 
the country use mostly ship scraps as input material. In most cases these input materials are not quality checked hence arbitrary. Input of human capital comes mainly from the families and surroundings of clusters. These workers are completely unskilled initially. Over years of work, they gain skills and in many case later forms independent shops themselves. The sector is running on outdated technology. In countries where this sector is well established like China, Japan or India, use of modern technology is very pervasive. CNC (Computerized and Numeric Controlled) technology is so common in these countries. In Bangladesh's case, CNC is very rare. Only few big firms use CNC technology. Most shops depend on intuitions and previous designs as far as designs and execution is concerned. Trial and error method is used in day to day operation.

Owners and managers of the sector have no formal financial and managerial training. They do not have any knowledge of the modern market system or mechanism. The term "value chain" is completely unknown to them while people with knowledge of the sector are asking the local light engineering sector to align with the global value chain. Owners and managers of the sector do not have any modern marketing capability either. They work on order by order basis. Most of the shops opens in the morning and waits for an order to be placed. These orders are on random basis. In most cases shops really have to depend heavily on luck for someone to show up. If there was regular marketing initiative, this would not have happened. The light engineering entrepreneurs lack contacts with foreign companies or international R \& D firms which is necessary for technical improvement and for seeking export markets.

In Bangladesh there are various clusters of light engineering firms in different parts of the country. Some notable of these clusters are Bogra which is renowned for agriculture machinery, Jessore which is notable for auto part or Dhaka and surrounding for bicycle, capital machinery and construction equipment. The sector is represented by Bangladesh Engineering Industry Owners' Association (BEIOA) which is the central organization.

\section{Sub Sectors of Light Engineering}

Although there are lots of limitations of the light engineering sector of the country, the sector supplies spare parts and machineries to other sectors. Following list of sub sectors is found in publication published on the occasion of $2^{\text {nd }}$ International Industrial \& Engineering Technology Trade Show \& Symposium [2].

1. Agriculture Machinery \& Spares

2. Motor launch and Marine Transport Spares

3. Textile Machinery and Spares

4. Jute Machinery and Spares

5. Tea plant Machinery and Spares

6. Construction Machinery and Spares

7. Bread, Biscuit and Food Processing Machinery and Spares

8. Metal Furniture

9. Paper and Pulp Machinery and Spares

10. Mold and Dies

11. Component \& Spares of Gas Transmission and Distribution

12. Printing and Packaging Machinery and Spares

13. Poultry Machinery and Spares

14. Kitchen Wear and Bathroom Fittings

15. Metal Product and Hard Ware

16. LP GAS Cylinder \& Fire Extinguisher

17. Pharmaceutical Machinery and Spares

\section{Spare Parts Business}

The sector supply's both complete machine and spare parts of complete machineries. In fact spare parts business is one of the prime businesses of the sector. The reason for such is that over years the sector has grown tremendous capability of emulating spare parts of any machine. For that reason spare parts business comes from the two sources, first for local made machineries and then from any spare parts demanded for almost any machinery.

However, local spare parts business is dominated by the spare parts imported from other countries most notable of those being China.

\section{Rationale of the Study}

Study done so far on the sector has concentrated on the sector as a whole, from a macro perspective. Specific study on demand side dynamics has not been taken up yet. Exclusive study on demand side dynamics will reveals why local spare part sector is dominated by imported spare parts. 


\section{Objectives}

The broad objective of this research is to study the demand dynamics of light engineering sector of the Bangladesh, with particular reference to products produced by small and medium enterprises (SMEs).

Specific objectives of the study are:

a) to measure the perceptions and attitudes of buyers involving the quality of spare parts produced by local light engineering sector, and

b) to come up with recommendations on how may local light engineering enterprises in spare parts withstand competition from imported spare parts.

\section{Scope of the study}

Light engineering sector supplies a wide range of complete machineries and spare part. However, scope of this study will be limited to spares parts supplied by the light engineering industry of the country. Output of small shops which sprawl in puran Dhaka (Old Dhaka) area are included. Some of the bigger firms which have also been making light engineering products are not part of this study.

\section{Methodology}

This study relied on both primary and secondary sources of information. Primary data was collected from 42 institutional buyers through structured questionnaire survey. The findings were further validated through depth interviews (DIs) with 14 leading industry insiders, entrepreneurs and experts. The survey was conducted on the technicians and purchase managers (of institutional buyers of spare parts) who have ample influence on purchase decision. They were identified by using a convenience sampling technique. On the other hand, DIrespondents were selected through snowballing technique.

Secondary data were collected from articles, journal publications and relevant web sites.

\section{Findings}

Structured questionnaires were circulated among the technicians of different companies. Technicians are the one who directly influence purchase decisions of spare parts. Questionnaire was designed to measure the perceptions and attitudes of the buyers. Furthermore, questionnaire was designed to compare attitudes and perceptions of buyers between local spare parts and imported spare parts.

\section{Frequency of Purchase}

Purchase frequency is very high in local spare parts sector. Question was asked about how often they make purchase. $95.2 \%$ of respondents say that they purchase on weekly basis. This is indicative of the fact that demand for spare parts is very high. Purchase activities keep on going and spare parts are very fast moving item in the market.

\begin{tabular}{|c|c|c|}
\hline \multicolumn{3}{|l|}{ Purchase frequency } \\
\hline & Frequency & Percent \\
\hline Weekly & 40 & 95.2 \\
\hline Once in every six months & 2 & 4.8 \\
\hline Total & 42 & 100.0 \\
\hline
\end{tabular}

\section{Finishing}

Respondents were asked to give scores on finishing on a 5 point Likart scale where 5 was the highest and 1 was lowest. Following table shows that average scores were 3.14 and standard deviation was .683.

\begin{tabular}{|l|l|l|}
\hline \multicolumn{2}{|l|}{ Finishing } \\
\hline \multicolumn{3}{|l|}{} \\
\hline Mean & $\mathrm{N}$ & Std. Deviation \\
\hline 3.14 & 42 & .683 \\
\hline
\end{tabular}

Further, following table shows that $66 \%$ respondents leaned towards middle point 3 while only $26.2 \%$ gave 4 to finishing. Average value 3.14 is indicate of the fact that respondent did not regard local spare parts quality to be on the superior side.

\begin{tabular}{|c|c|c|}
\hline Scores on fi & & \\
\hline & Frequency & Percent \\
\hline 1 & 2 & 4.8 \\
\hline
\end{tabular}




\begin{tabular}{|l|l|l|l|}
\hline \multirow{4}{*}{} & 2 & 1 & 2.4 \\
\cline { 2 - 4 } & 3 & 28 & 66.7 \\
\cline { 2 - 4 } & 4 & 11 & 26.2 \\
\cline { 2 - 4 } & 5 & 0 & 00 \\
\cline { 2 - 4 } & Total & 42 & 100.0 \\
\hline
\end{tabular}

Price

Price of the product is a very important factor for local spare parts. It has been found from interviews that a purchaser hops from shop to shop for a small reduction of price. Questions were asked to the respondents that whether they were happy with the price of local spare parts. 71.4\% responded that they were satisfied with the price while $28.6 \%$ were not. Spare parts makers offer product at a very low price. On top of that purchasers can do serious bargain regarding the price. The fact that $71.4 \%$ were satisfied with the price shows that bargain power is on the buyer's side. On quality parameters local parts do not score very high, in fact average. When buyers are satisfied with the price this means buyers are able to bargain down price which corresponds to the perceived quality.

\section{Productivity}

For any manufacturing company, productivity is a very important factor. Productivity in this case is a complex factor. Local spare parts may save time for purchase; it may reduce the need for other input requirements of the machines. All these factors may lead more or less or same productivity as imported spare parts. Questions were asked whether local spare parts increase productivity of the company. Following table shows that 52.4\% respondents answered that local or imported spare parts have the same performance as far as productivity is concerned. $33.3 \%$ said local spare parts actually increase their productivity.

\begin{tabular}{|l|l|l|l|}
\hline \multicolumn{4}{|l|}{ Do local spare parts increase productivity? } \\
\hline \multicolumn{1}{|c|}{} & Yes & Frequency & Percent \\
\cline { 2 - 4 } & No & 14 & 33.3 \\
\cline { 2 - 4 } & Same as imported parts & 6 & 14.3 \\
\cline { 2 - 4 } & Total & 22 & 52.4 \\
\hline
\end{tabular}

\section{Attributes of the parts}

Several attributes regarding local spare parts were studies in comparison with imported spare parts. Questions were asked whether buying local spare parts were time saving, whether respondent feels riskier using local spare parts, whether local spare parts consumes more machine oil, whether local spare parts breaks down more often, whether local spare parts need more repair and whether local spare parts need more maintenance. Summary of responses on these parameters are given below.

\section{Whether purchase of local spare partssaves time}

\begin{tabular}{lr|r} 
& Frequency & Percent \\
\hline Yes & 29 & 69.0 \\
\hline No & 6 & 14.3 \\
\hline Same as imported parts & 7 & 16.7 \\
\hline Total & 42 & 100.0 \\
\hline
\end{tabular}

\section{Whether use of local spare parts feels risky}

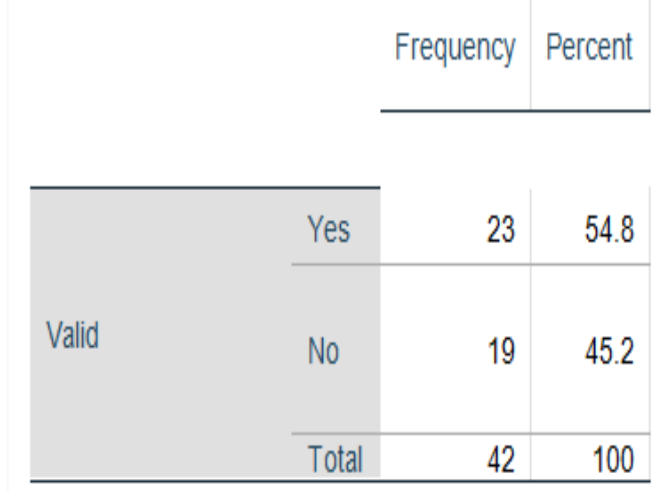


Whether local spare parts consumes more machine oil

\begin{tabular}{l|r|r} 
& Frequency & Percent \\
\hline Yes & 17 & 40.5 \\
\hline No & 6 & 14.3 \\
\hline $\begin{array}{l}\text { Same as } \\
\text { imported parts }\end{array}$ & 19 & 45.2 \\
\hline Total & & \\
\hline
\end{tabular}

Whether local spare parts breaks down more often

\begin{tabular}{lr|r} 
& Frequency & Percent \\
\hline Yes & 23 & 54.8 \\
\hline $\begin{array}{l}\text { Same as imported } \\
\text { parts }\end{array}$ & 19 & 45.2 \\
\hline Total & 42 & 100.0 \\
\hline
\end{tabular}

Whether local spare parts consumes more electricity

\begin{tabular}{lr|r} 
& Frequency & \multicolumn{1}{c}{ Percent } \\
\hline Yes & 2 & 4.8 \\
\hline No & 14 & 33.3 \\
\hline $\begin{array}{l}\text { Same as } \\
\text { imported } \\
\text { parts }\end{array}$ & 26 & 61.9 \\
\hline Total & & \\
\hline
\end{tabular}

Whether local spare parts need more repair

\begin{tabular}{lr|r} 
& Frequency & \multicolumn{1}{c}{ Percent } \\
\hline Yes & 29 & 69.0 \\
\hline $\begin{array}{l}\text { Same as } \\
\text { imported parts }\end{array}$ & 13 & 31.0 \\
\hline Total & & \\
\hline
\end{tabular}

Whether local spare parts maintenance is easier

\begin{tabular}{lr|r} 
& Frequency & Percent \\
\hline Yes & 20 & 47.6 \\
\hline No & 13 & 31.0 \\
\hline $\begin{array}{l}\text { Same as } \\
\text { imported parts }\end{array}$ & 9 & 21.4 \\
\hline Total & 42 & 100.0 \\
\hline
\end{tabular}

\section{Confidence on Certification}

Certification of products is very important in the mind of customers. Most local spare parts are without any certification and without brand logo. In many cases buyer feels vulnerable to buy such spare parts. Question was asked whether they thought certification from any agency, for example BSTI (Bangladesh Standard Testing Institute) would have been better. $100 \%$ respondents answered they would like it to be so. This is indicating of the fact how vulnerable buyer's minds are in the absence of any certification. In fact from interviews it was found that in the absence of brand logo or certification buyers feel shaky because when they come back for any repair, sellers often deny that they had actually made the product in the first place.

\section{Overall Scores}

Respondents were asked to grade local spare parts on Likart scale of 1 to 5.5 was the highest while 1 was the lowest. Following table is the summary of scores provided by respondents. $50 \%$ respondents gave 3 out of 5 which the mid result of five point Likart scales.

Overall Marks given to local spare parts

\begin{tabular}{|c|c|c|c|}
\hline & & Frequency & Percent \\
\hline \multirow[t]{4}{*}{ Valid } & 3 & 21 & 50.0 \\
\hline & 4 & 11 & 26.2 \\
\hline & 5 & 10 & 23.8 \\
\hline & Total & 42 & 100.0 \\
\hline
\end{tabular}

\section{Overall marks, average}

overall mark

\begin{tabular}{|c|c|c|}
\hline Mean & $\mathrm{N}$ & Std. Deviation \\
\hline 3.74 & 42 & .828 \\
\hline
\end{tabular}




\section{Comments on attributes}

From the interviews and from primary data collected it is sufficiently clear that in buyers' minds attributes score similar between local and imported parts. In fact $69 \%$ respondents said purchasing of local parts saves their time. $54.8 \%$ felt riskier using local parts where $45.2 \%$ did not. $45.2 \%$ respondents said consumption of machine oil, which is an important input, is same as imported spare parts while $40.5 \%$ said local parts did consume more machine oil. $61.9 \%$ respondents said imported and local spare parts consume same amount of electricity. 54.8\% respondents said local spare parts break down more often while $45.2 \%$ said it did not. $69 \%$ respondents said local spare parts require more repair. $47.6 \%$ said maintaining of local parts was easier then imported spare parts.

The point is, from the data it is clear that neither local spare parts nor imported one has clear lead on product attributes. If that is the case then there must be facts that can explain pervasiveness of imported spare parts. Following facts can explain such pervasiveness:

a) Better perception regarding finishing

b) Better marketing and distribution initiative

c) Scale of production

d) Comparable cost

At this point there are many issues to solve if local spare parts makers want to be the prime choice in the local market. If following things can be done local spare parts can claim the market of spare parts. However, some of these recommendations are farfetched and some could be implemented immediately.

\section{Recommendations}

From the primary data and depth interviews some of the facts have been found which need attention if Bangladeshi spare parts are to be made as prime choice of local buyers. These factors are interrelated and fixing one may lead to fixing other as well. These factors are discussed below.

\section{Fixing Price Sensitivity Issue}

Price sensitivity is an important factor for the local spare parts industry as many of the companies who purchase spares parts are really sensitive about the cash. It has been observed that purchasers shift shops for just a little variation in the price. On top of that imported spare parts are affordable and perceived to be of higher quality. Local industry must come up with a price which corresponds to their perceived quality. Local industry must also agree on a base level price agreed by all so that unhealthy competition is mitigated or reduced to zero. At present local spare parts makers are cutting each other throats not foreign spare parts makers.

\section{Solving negative perceptions about quality}

As was said earlier quality perceptions are big factors in spare parts industry. It has been embedded in the mind of purchasers that Bangladeshi products are of less quality. This perception has to be eliminated by supplying products which are of higher quality and aesthetically beautiful.

\section{Targeting niche products}

From the interviews it has been found that Bangladeshi workers are really good at making some products such as chains and ball bearing. Local industries are buying these things from the local market with much satisfaction. From interviews experience it can be said that local industries can target niche products and be exceptionally good at that.

\section{Branding}

Another fact is that local products does not have a least branding. In fact local spare parts products are far from making it to a branded product. They work mostly on order basis. These orders are highly unreliable. Local spare parts makers really are at the mercy of luck. If somebody shows up in the shop, only then the shop has some work. Branded parts could have solved the problem. If products were branded, customers would have looked for the brand instead of a shop. That would have saved the shop owner from the mercy of pure luck.

\section{Durability}

Durability of local spare parts are very big issue for local consumer. It has been found that local products are somewhat less durable than the imported one. The reason for that is the quality of input which are mostly sub standards and without any grading. Input materials could be checked before making any product so that makers can come out with the spare parts which corresponds to required quality of the buyer.

\section{Multi quality}

Local firms can also concentrate on making multi quality products targeting the varied needs as well as buyer segments.

\section{CNC (Computerized and Numeric Controlled) Machine}

$\mathrm{CNC}$ has been in discussion for some time now in the local industry. As of now, most local spare parts makers rely on their hands on experience which they have gained over the years. Many of parts need adjustments after making because local shops are working on trial and error basis. A CNC driven lathe machine would solve the problem and bring efficiency. 


\section{Use of Robotics}

Given the condition of local industry at this point time use of robotics to make spare is a far cry. All developed countries use robotics to gain efficiency and scale. At some point in time local industry has to concentrate on using robotics for making spare parts to gain in terms of efficiency and scale.

\section{Use of Operations management}

Another issue which can also be called a far cry at this point in time but will have to be adopted eventually is the use of operations management. Operations management will enable shops to take their constraints into account and produce much more realistically.

\section{Research and Development}

Finally there has not been any impactful research in the area regarding product development. The research must start from need assessment of parts across the industries.

\section{Conclusion}

From the depth interviews and from the conservations with the users of local spare parts conclusion can be drawn that there is little difference between local and imported spare parts. Yet imported spare parts have pervaded local market due to such attributes as superior finishing, aggressive marketing and ability to supply in large scale. This paper has come up with specific recommendations about how local spare parts makers can withstand the competition from imported spare parts. Some of these recommendations such as use of operations management and use of robotics are farfetched. However, immediate interventions may involve SME capacity building coupled with use of CNC machine, marketing and branding support. These initiatives are expected to initiate the process of market-responsive growth of local light engineering enterprises.

\section{Acknowledgement}

The authors gratefully acknowledge the contribution of Professor Dr. Kamal Uddin of Bangladesh University of Engineering and Technology and Md. Abdur Razzak President of Bangladesh Engineering Industry Owners' Association, Md. Masum Talukdar, Consultant of Bangladesh Engineering Industry Owners' Association. Mosharrof Hossain Mir, Office Secretary of Bangladesh Engineering Industry Owners' Association. Appreciation also goes to all the light engineering entrepreneurs and institutional buyers who have responded to authors' research queries.

\section{References}

[1]. BGMEA. (n.d.). BGMEA. Retrieved January 9, 2017, from BGMEA: http://bgmea.com.bd/home/pages/TradeInformation

[2]. BIET. (2011). 2nd International Industrial \& Engineering Technology Trade Show \& Symposium. Dhaka: BIET.

[3]. Bureau, E. P. (2016, 11 2). EPB. Retrieved from EPB: http://www.epb.gov.bd/

[4]. Council, B. P. (2016, November 3). Business Promotion Council. Retrieved from Business Promotion Council: http://bpc.org.bd/lepbpc_current_sector_profile.php

[5]. INSPIRED. (2013). Technical Report Light Engineering Sector Includes a Value Chain Analysis and Proposed Action Plan . Dhaka: INSPIRED.

[6]. (2010). Light Engineering Industry in Bangladesh: A Case Study. Dhaka: Bangladesh Institute of Development Studies .

[7]. McVay, D. A. (2006). Market Development in Practice Sector Development and Business Service Strategy. Geneva: Press. 